\title{
Review
}

\section{Who Uses CAM? A Narrative Review of Demographic Characteristics and Health Factors Associated with CAM Use}

\author{
Felicity L. Bishop and G. T. Lewith \\ Complementary Medicine Research Unit, School of Medicine, University of Southampton, Hampshire, UK
}

\begin{abstract}
Complementary and Alternative Medicines (CAM) are used by an extensive number of patients in the UK and elsewhere. In order to understand this pattern of behavior, it is helpful to examine the characteristics of people who use CAM. This narrative review collates and evaluates the evidence concerning the demographic characteristics and health status factors associated with CAM use in community-based non-clinical populations. A systematic literature search of computerized databases was conducted, and published research papers which present evidence concerning associations between CAM use and demographic and health characteristics are discussed and evaluated. The evidence suggests that people who use CAM tend to be female, of middle age and have more education. In terms of their health, CAM users tend to have more than one medical condition, but might not be more likely than non-users to have specific conditions such as cancer or to rate their own general health as poor. The multivariate studies that have been conducted suggest that both demographic and health characteristics contribute independently to CAM use. In conclusion, demographic characteristics and factors related to an individual's health status are associated with CAM use. Future research is needed to address methodological limitations in existing studies.
\end{abstract}

Keywords: CAM use - patient characteristics - review

\section{Introduction}

Considerable number of people are turning to Complementary and/or Alternative Medicines (CAM). For example, in the UK, $46 \%$ of the population can be expected to use one or more CAM therapies in their lifetime (1). This phenomenon has inspired a body of literature directed at examining who uses CAM and why they do so. Before developing theories to explain the popularity of CAM it is essential to first determine who is using CAM. What are the characteristics of the people who are involved in what could be termed a 'patient-led revolution' in the demand for health care? Existing reviews have tended to focus on prevalence rates of CAM use in specific clinical populations [e.g. diabetes (2), asthma (3)]

For reprints and all correspondence: Dr Felicity L. Bishop, PhD, Complementary Medicine Research Unit, Aldermoor Health Centre, Aldermoor Close, Southampton SO16 5ST, UK. Tel: + 44-0-2380241072; Fax: +44-0-23-80701125; E-mail: flb100@soton.ac.uk or need updating to incorporate the additional evidence published in recent years and to examine CAM use in countries other than the USA (4). The purpose of this review is to collate and evaluate the published evidence concerning the demographic characteristics and health status factors that are associated with CAM use. Our research questions can be summarized as:

1. What is known about the demographic characteristics of people who use CAM?

2. What is known about the health status of people who use CAM?

3. How have the above questions been addressed in the literature and how might future studies best improve our understanding in this area?

We have chosen to focus this review on studies carried out in the general population (i.e. community-based rather then clinical samples) in order to obtain a clearer picture of the general demographic and health trends in CAM use. 
By summarizing this large body of literature it should be possible to reach a more comprehensive understanding of both the characteristics associated with CAM use and the most appropriate directions for future research in this area.

\section{Methods}

\section{Search Strategy}

The comprehensive narrative review presented below is based on material derived from a systematic literature search conducted using six computerized databases (MedLine, PsycInfo, AMED, CINAHL, Embase and Web of Knowledge). We attempted to identify all surveys of community-based adult samples that documented statistical associations between CAM use and demographic and/or health factors, and were published in English in peer-reviewed journals between January 1995 and December 2006 (inclusive). We searched for the following combination of keywords:

1. Complementary Medicine or Alternative Medicine

2. Epidemiology or Prevalence or Survey and

3. Population or Community or National

Abstracts and articles were read for relevance to the research question. Articles were selected for review if they met the following topic-related criteria: definition of CAM employed is broadly consistent with the NCCAM definition of CAM; assess CAM use (insufficient to measure attitudes to CAM); sample includes community-based adults (i.e. not purely clinical or pediatric populations); assess either demographic characteristics (at least one of age, gender, income, education) and/or health-related characteristics (at least one of presence of specific condition(s), self-rated general health, number of conditions). Articles which did not meet the following quality-related criteria were excluded: original empirical study (i.e. not an editorial or letter or other type of commentary); present inferential statistics (i.e. not just percentages or frequencies) concerning associations between CAM use and demographic and/or health-related factors. The papers selected for inclusion are reviewed below for further quality-related criteria (e.g. definition of terms, measurement tools). Figure 1 shows how the database search and article selection process resulted in 110 articles being included in this review $(1,5-113)$.

\section{Review Strategy}

Study characteristics, methodological details and results of statistical analyses were extracted from our 110 articles and entered into a spreadsheet to facilitate data sorting and review. Sixty-four studies that met our inclusion criteria reported more than one statistical analysis that is relevant to our research questions of whether demographic and health factors are associated with CAM use. Some of these studies reported subgroup analyses, for example examining the statistical predictors of CAM use amongst men and women separately. Others examined the statistical predictors of different types of CAM use, for example examining use of each of the five separate NCCAM categories of CAM. We therefore extracted results of all relevant reported analyses from each paper.

Having read all 110 papers in detail the demographic and health variables that were commonly analyzed in relation to CAM use were selected for this review. We thus decided to focus on whether CAM use is associated with specific demographic factors (gender, age, income, education and ethnicity) and specific health factors (having specific conditions, general physical health, general mental health). We extracted information from the original studies concerning the results of any tests of association between these variables and CAM use, as well as a number of methodological details (e.g. sample characteristics). To examine the consistency of the evidence surrounding associations between each of these factors and CAM use, we calculated the proportion of analyses reporting statistically significant associations. For example, we counted the number of analyses (e.g. $t$-tests, regressions) reporting a significant association between gender and CAM use and then divided this by the total number of tests (across all our studies) of whether gender is associated with CAM use. We repeated this procedure separately for bivariate analyses (testing the association between CAM use and one other variable) and multivariate analyses (testing the association between CAM use and one other variable while taking into account the influence of additional variables).

\section{Results}

\section{Study Characteristics}

\section{Design and Participants}

Much of the research on CAM use to date has been conducted in the US. Indeed, of the 110 studies meeting our inclusion criteria $70(64 \%)$ were carried out in the US, $10(9 \%)$ in Australia, $5(5 \%)$ in the UK and $4(4 \%)$ in Canada. The remaining studies were carried out in Israel $(\mathrm{n}=3)$, Turkey $(\mathrm{n}=2)$, Italy $(\mathrm{n}=1)$, the Scandinavian countries $(n=8$ in total), Asian countries $(n=5)$, South Africa $(\mathrm{n}=1)$ and Canada and North America together $(n=1)$. In the UK the NHS is the main provider of conventional health care, providing a service that is free for all at the point of use, while the private sector is the main provider of CAM (1). In the US, the private sector is the main provider of both conventional and complementary medicine. In both the UK and the US the majority of CAM 


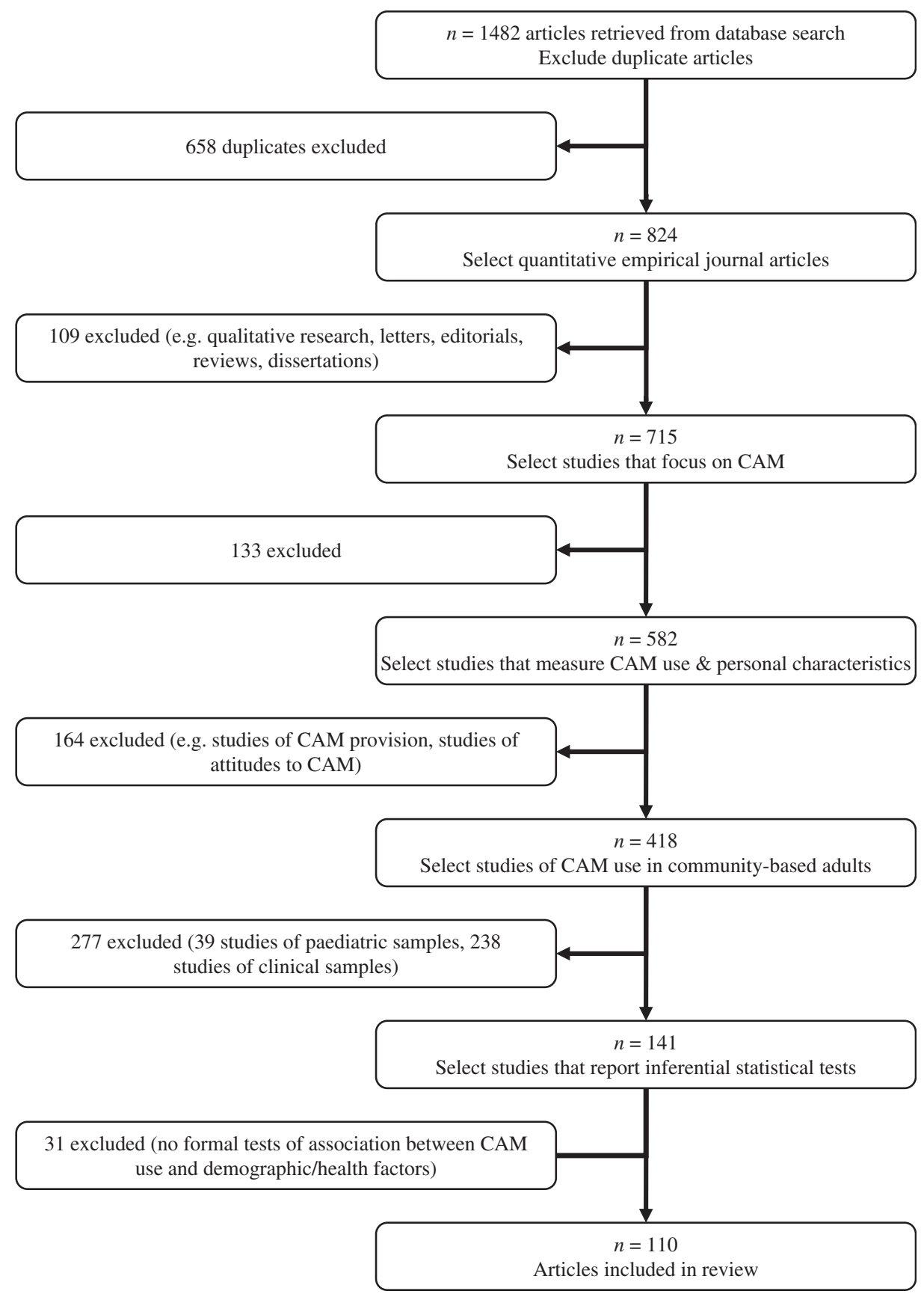

Figure 1. Identification and selection of articles for inclusion in this review.

is provided privately, as most US insurance companies offer only limited cover for CAM. ${ }^{2}$ These cultural issues need to be remembered when interpreting the results of individual studies.

The vast majority of studies $(107,97 \%)$ employed crosssectional designs. This means that we know very little about the timelines involved in CAM use. While this is of little consequence when considering demographic associations with CAM use it is of more importance when considering the relationship between health and illness and CAM use: it is not sufficient to assume that particular conditions have a causal role in CAM use, we must generate prospective data to investigate whether people initiate CAM use prior or consequent to developing specific conditions.

We have only included studies based on adult samples, but there was still a considerable range across the studies in terms of the age range of participants. 37 studies (34\%) did not specify any age-related inclusion criteria, beyond reporting sampling adults. Most commonly studies $(22,20 \%)$ required participants to be 18 years and over. A further 10 studies focused on participants aged 65 years and older. The remaining 78 studies used a wide variety of other age-related criteria (32 different criteria in 
total), including for example 18-64 years, 18-80 years, 4550 years, 77 years and older, 45-75 years, 52 years and older. This wide variety of age related inclusion criteria across the individual studies makes it difficult to make simple comparisons between studies when considering the relationship between age and CAM use.

\section{Methodological Indicators of Study Quality}

In order to assess the representativeness of individual studies it is important to consider the nature of the sample obtained and the way in which it is obtained, as well as the overall sample size and response rate. Of the 110 studies included in our review, $62(56 \%)$ report using a national sample of participants while the remainder used regional or more local samples. Many of the nationally representative studies utilized large datasets from established surveys, including the US National Health Interview Survey (analyzed in 19 studies) and the Medical Expenditure Panel Survey (5 studies). Ninety-eight studies (89\%) report using standard sampling techniques (e.g. randomized or probability based sampling with or without stratification), while the others either reported using a convenience sample or did not specify their sampling methods. Eighty studies $(73 \%)$ reported response rates, which ranged from the slightly disappointing $38 \%$ to an impressive $100 \%$. The sample sizes employed in the studies also varied greatly, ranging from 128 to over 600000 in a study based on participants' insurance records.

The majority of our studies $(76,69 \%)$ offer their readers a definition of CAM. Furthermore, only three did not report how they defined CAM for their participants. The definitions of CAM provided to participants varied across studies, but most provided a list of specific CAM therapies and many asked participants about their use of these therapies over a specific time period (e.g. past 12 months). The most commonly cited definition of CAM was that formalized by the National Centre for Complementary and Alternative Medicine ('CAM is a group of diverse medical and health care systems, practices and products that are not presently considered to be part of conventional medicine') $(6,23,48,49,76,85,101,105)$; many other studies used similar definitions to NCCAM $(24,57,63)$ while some focused more on specific therapies as exemplars of CAM, for example supplements (44), acupuncture (21), faith healing (50).

Most of the 110 studies reviewed provided surprisingly little detail concerning the instruments used to measure people's CAM use, demographic and health characteristics. Only 24 studies reported using previously validated measures (for example established measures of health status such as the SF-36). Eight studies reported re-using or adapting measures from previous studies of CAM use, while nine studies mentioned or described a pilot-testing process that was used in the development of their survey instruments. The use and reporting of valid and reliable measurement instruments in CAM use surveys need to be improved.

\section{Demographic Factors Associated with CAM Use}

Knowledge of the demographic characteristics of CAM users provides insights into not only who is likely to use CAM but also some of the factors that may influence the choice to use CAM. Table 1 summarizes the proportions of our 110 studies that reported significant associations between CAM use and gender, education, income, age and ethnicity.

\section{Gender}

There is reasonably consistent evidence that women are somewhat more likely than men to use CAM. Of 151 bivariate tests of whether gender is associated with CAM use, 95 found that women were more likely to use CAM than men, 2 found the converse and the remaining 54 tests found no statistically significant association between gender and CAM use. The findings from multivariate analyses that included gender alongside other possible predictor variables show the same trend, of 116 analyses 71 found that women were more likely to use CAM than men, 4 found the converse and 41 found no statistically significant association between gender and CAM use. The majority of studies thus report that women are more likely than men to use CAM, and this has been found in national surveys in both the UK (1) and US (101). For example in one US study $39 \%$ of women and $31 \%$ of men had used CAM in the past year. ${ }^{101}$ However some national studies have not found significant gender differences $(8,100)$ and the small number of tests finding men more likely to use CAM $(41,48,73)$ remind us that while CAM use is more common in women it is far from unheard of in men.

It is important to remember that women also tend to seek help from orthodox health care professionals more than men (114). However, in a study of health care utilization conducted with older adults in Italy, $79 \%$ of people who used only CAM were female, $72 \%$ of people who used both CAM and conventional medicine were female, $61 \%$ of people using only conventional medicine were female, while $46 \%$ of people using no health care were female (19). This suggests that while women are more likely than men to use any form of health care, this tendency might be amplified when considering CAM use.

\section{Education and Income}

It has been suggested that CAM use is more common among the well-educated and wealthy. There is stronger evidence for the former proposition than there is for the latter. Of 138 bivariate tests of whether education is associated with CAM use, 92 found that CAM use increases with education while 8 found that CAM use is 
Table 1. Summary of the proportion of studies reporting significant associations between CAM use and demographic factors

\begin{tabular}{|c|c|c|c|c|}
\hline \multirow[t]{2}{*}{ Demographic factors } & \multicolumn{2}{|c|}{$\begin{array}{l}\text { Number of tests of association } \\
\text { with CAM use }\end{array}$} & \multicolumn{2}{|c|}{ Proportion of tests finding significant association with CAM use } \\
\hline & Bivariate & Multivariate & Bivariate $(\%)$ & Multivariate $(\%)$ \\
\hline Gender & & & 1 (men more likely to use CAM) & 3 (men more likely to use CAM) \\
\hline \multirow[t]{2}{*}{ Age } & 161 & 134 & 19 (CAM use increases with age) & 19 (CAM use increases with age) \\
\hline & & & $\begin{array}{l}22 \text { (curvilinear relationship, CAM } \\
\text { use peaks in middle age) }\end{array}$ & $\begin{array}{l}13 \text { (curvilinear relationship, CAM } \\
\text { use peaks in middle age) }\end{array}$ \\
\hline Ethnicity & 97 & 91 & 54 & 63 \\
\hline \multirow[t]{2}{*}{ Education } & 138 & 137 & $\begin{array}{l}67 \text { (CAM use increases with } \\
\text { education) }\end{array}$ & $\begin{array}{l}61 \text { (CAM use increases with } \\
\text { education) }\end{array}$ \\
\hline & & & $\begin{array}{l}8 \text { (CAM use decreases with } \\
\text { education) }\end{array}$ & $\begin{array}{l}4 \text { (CAM use decreases with } \\
\text { education) }\end{array}$ \\
\hline \multirow{2}{*}{ Income } & & & 9 (CAM use decreases with income) & 4 (CAM use decreases with income) \\
\hline & & & $\begin{array}{l}1 \text { (curvilinear relationship, CAM } \\
\text { use peaks in middle incomes) }\end{array}$ & \\
\hline
\end{tabular}

more common in people who have less education. Thirty-seven tests found no statistically significant association between education and CAM use. The findings from multivariate analyses that included education alongside other possible predictor variables show the same trend, of 137 analyses 83 found that CAM use increases with education, 5 found the converse and 49 found no statistically significant association between education and CAM use. CAM use was associated with higher education in a range of studies from different countries, including: Australia (61), Canada (66), Israel (94), Scandinavia (42), and the USA (47). Education has been associated with CAM use in a wide range of studies and such consistency warrants the conclusion that higher education predicts CAM use.

The association between CAM use and education could be confounded by income: CAM use might increase with education because people with more education also tend to have higher incomes, i.e. they can better afford to use CAM. However, the evidence for income as a predictor of CAM use is rather less consistent than that for education. Of 85 bivariate tests of whether income is associated with CAM use, 35 found that CAM use increases with income while 8 found the converse and 41 found no statistically significant association between income and CAM use. The findings from multivariate analyses show the same trend, of 91 analyses 29 found that CAM use increases with income, 4 found the converse and 58 found no statistically significant association between income and CAM use.

To explore whether income is responsible for the association between education and CAM use it is also necessary to examine those studies that test the multivariate association between both income and education and CAM use. Of 88 such tests, $24 \%$ found that neither income nor education were associated with CAM use while 30\% found that both factors were independently associated with CAM use. A further 39\% of tests found that education but not income was significantly associated with CAM use while only $8 \%$ reported that income but not education was associated with CAM use. This pattern suggests that income does not account for the documented association between education and CAM use. One major US survey found that while education was associated with CAM use, income was not, suggesting that wealth cannot be the only explanation (8) and peoples' awareness of and ability to seek out information about CAM is probably associated with educational attainment. This is supported by the finding that higher education was associated with use of acupuncture and relaxation, while less education was associated with use of chiropractic (85). In this survey participants who used chiropractic tended to live in the area of the US where it originated, and so might be expected to have a high awareness of chiropractic regardless of their level of education.

\section{Ethnicity}

The evidence concerning ethnicity and CAM use is complex and general trends are difficult to ascertain. Fifty-two out of 97 bivariate tests and 57 of 91 multivariate tests found significant associations between ethnicity and CAM use. There were 38 reports of tests showing that people from ethnic minorities use CAM less 
Table 2. Summary of the proportion of studies reporting significant associations between CAM use and health factors

\begin{tabular}{|c|c|c|c|c|}
\hline \multirow[t]{2}{*}{ Health factors } & \multicolumn{2}{|c|}{$\begin{array}{l}\text { Number of tests of association } \\
\text { with CAM use }\end{array}$} & \multicolumn{2}{|c|}{ Proportion of tests finding significant association with CAM use } \\
\hline & Bivariate & Multivariate & Bivariate $(\%)$ & Multivariate $(\%)$ \\
\hline Anxiety or depression & 22 & 17 & 50 & 47 \\
\hline Cancer & 44 & 22 & $\begin{array}{l}30 \text { (Cancer increases CAM use) } \\
23 \text { (Cancer decreases CAM use) }\end{array}$ & 86 (Cancer increases CAM use) \\
\hline Chronic conditions (n) & 20 & 31 & 75 & 42 \\
\hline Self-rated general health & 55 & 60 & $\begin{array}{l}38 \text { (CAM users worse health) } \\
5 \text { (CAM users better health) }\end{array}$ & $\begin{array}{l}38 \text { (CAM users worse health) } \\
10 \text { (CAM users better health) }\end{array}$ \\
\hline Psychological health & 25 & 27 & $\begin{array}{l}36 \text { (CAM users worse health) } \\
8 \text { (CAM users better health) }\end{array}$ & $\begin{array}{l}44 \text { (CAM users worse health) } \\
11 \text { (CAM users better health) }\end{array}$ \\
\hline
\end{tabular}

than whites, and 15 showing the converse. Two UK-based studies report different findings: Cappuccio et al. (22) found that people of African ethnicity in London were more likely than Caucasians to use over-the-counter alternative medicines, while Harrison et al. (44) found that in North-West England whites were more likely than people from ethnic minorities to use herbal supplements. The different categories used impair interpretation across multiple studies and any examination of ethnicity and CAM use would appear to benefit from examining specific types of CAM, rather than looking at CAM use in general (49); a more detailed literature review that focuses just on ethnicity is required to more fully understand the evidence concerning CAM use and ethnicity.

\section{Age}

The relationship between age and CAM use has been examined in a variety of ways and in a wide range of samples. Of 161 bivariate tests of whether age is associated with CAM use, 98 found a statistically significant association between age and CAM use. The nature of reported associations between age and CAM use is mixed, with 35 studies suggesting middle-aged people are more likely to use CAM (compared with older or younger adults) while others suggest more linear associations between CAM use and either older age (30 studies) or younger age (33 studies). The findings from multivariate analyses that included age alongside other possible predictor variables show the same pattern, of 134 analyses 71 found a significant association between age and CAM use. Approximately equal numbers of studies found a curvilinear association suggesting that middle-aged people are more likely to use CAM (18 studies), found that CAM use increases with age (26 studies) and found that CAM use decreases with age (27 studies). Thus while some studies have found a relationship between age and
CAM use, there is little consensus between studies beyond the observation that CAM users tend to be young or middle-aged and are less likely to be older adults. Conversely, studies of age and conventional medicine suggest that the young ( $<5$ years) and the elderly ( $>65$ years) make the most use of conventional medicine services such as GP consultations (115). As noted above, the wide range of ages included in these studies and different age categories employed makes the interpretation of these findings extremely difficult, without further more detailed data extraction which is beyond the scope of this review. Future research would better serve the cumulative scientific endeavor by developing and adhering to a consensus regarding how to categorize age for the purposes of analysis.

\section{Health Factors Associated with CAM Use}

Studies of health care utilization in conventional medicine have argued that perceived need in terms of physical and psychological symptoms and health status is one of the most important and immediate variables in explaining use of health services (116-119). In the context of CAM use it has been suggested that people who use CAM either suffer from chronic conditions that might not have been treated satisfactorily by conventional medicine or have life-threatening diseases and use CAM because they are experiencing psychological distress and will try anything that might offer a cure. Table 2 summarizes the proportions of our 110 studies that found significant associations between CAM use and some specific conditions as well as indicators of general physical and psychological health status.

\section{Diagnoses}

The wide range of diagnoses examined in the original studies renders meaningless any collapsing across studies 
on this variable. People use CAM for a wide range of physical and psychological conditions and even for no specific condition. Thomas et al. (1) found that the majority $(71 \%)$ of visits to CAM practitioners in their UK-based survey were made for musculoskeletal problems, while visits were also made for other health problems $(24 \%)$ and for health maintenance $(5 \%)$. In our dataset there were multiple analyses across studies that examined the impact on CAM use of arthritis, anxiety/depression, cancer and diabetes. In bivariate tests CAM use was associated with having arthritis in $53 \%$ of tests, with having anxiety or depression in $50 \%$ of tests, with having cancer in $30 \%$ of tests and with having diabetes in $24 \%$ of tests. The evidence for associations between these conditions and CAM use was thus relatively weak and inconsistent across studies. Contrary to stereotypical beliefs, these studies provide no strong evidence that having cancer increases the likelihood of using CAM; clearly future reviews could helpfully delve deeper and examine associations between CAM use and different types/stages of cancer.

\section{General Health Status}

A range of indicators of general health have been examined as potential predictors of CAM use. The majority $(75 \%)$ of studies considering the number of illnesses people report found that CAM use increases as people report higher numbers of chronic health conditions. Combined with the evidence reported above (that specific conditions are not consistently associated with CAM use), this evidence does not support the hypothesis that people use CAM mainly for life-threatening conditions but does suggest that CAM is often used by people who have chronic conditions.

The role of self-perceived health status has also been examined, with inconsistent results. Of 55 analyses of bivariate associations between CAM use and self-reported health status, 21 reported that CAM use is more common in people who have poorer self-perceived health while 3 found the converse. A small number of studies (25) examined the role of psychological health in CAM use: 14 tests found no significant association, 2 found that CAM use was associated with better psychological health while 9 found that CAM use was associated with poorer psychological health. Again this does not provide strong evidence for the stereotypical belief that CAM users have higher psychological morbidity. The inconsistent findings regarding health status and CAM use might be in part due to the cross-sectional designs employed in these studies: as mentioned above, prospective studies are essential in order to understand whether poor health (diagnosed or self-perceived) actually triggers CAM use, and how this relates to use of conventional medicine.

\section{The Relative Importance of Demographic Characteristics and Health Status}

It is likely that a number of demographic and health variables may be confounded, and studies that have conducted multivariate analyses can provide some insight into the possible co-variation between factors and also their relative importance. However, it can be difficult to interpret these studies as they have tended to include different combinations of variables, and when the same variables are included, they are not always measured in the same way. Table 3 summarizes 67 multivariate analyses of the demographic and health-related predictors of CAM use.

Overall, a number of larger studies from different countries suggest that both demographic and healthrelated variables are independent predictors of CAM use: neither demographic nor health factors are consistently more important predictors of CAM use In the UK, Harrison et al. (44) found that use of herbal supplements was associated with both demographic (e.g. middle-age, female gender, white ethnicity) and health factors (e.g. psychiatric morbidity), although self-perceived general health did not predict supplement use. In the US, Bausell et al. (12) again found that demographic (e.g. age over 30, female gender, higher education) and health factors (e.g. poorer physical health) were associated with visiting a CAM practitioner. Different combinations of demographic and health factors are found to be significant independent predictors of CAM use in studies from Australia (35), Canada (66), Denmark (79), Finland (62), Israel (94), Italy (19), and Sweden (70). Overall the evidence supports a role for both demographic and health factors in predicting CAM use. However the differences between the studies (Table 3) also highlight the importance of understanding specific types of CAM use in specific populations and suggest that trying to come up with a profile of CAM users in general is perhaps, after all, somewhat futile.

\section{Conclusions}

There have been few large-scale multivariate studies of CAM use conducted in the UK. However, the evidence from these studies combined with studies from other countries suggests that both demographic and health factors are associated with CAM use. People who use CAM tend to be of middle age (in the broadest possible terms), higher education and female gender. The evidence concerning whether CAM users have higher incomes is less consistent. In terms of their health, CAM users tend to have more than one health condition, but may not be more likely than non-users to have any one specific condition. We found inconsistent evidence concerning whether CAM users perceive their own health (physical or psychological) to be poorer than non-users. These conclusions are based on a general review of studies of CAM use. It is possible 
Table 3. Summary of multivariate analyses of CAM use demographic and health factors

\begin{tabular}{lllll}
\hline Study & $\begin{array}{l}\text { Sample characteristics and } \\
\text { sampling strategy }[n]\end{array}$ & $\begin{array}{l}\text { CAM use } \\
\text { variable }\end{array}$ & Significant predictors & Non-significant predictors \\
\hline
\end{tabular}

Arcury et al. (6)

Astin (8)

Bausell et al. (12)

Bazargan et al. (13)

Bell et al. (14)

Burke et al. (21)

Cherrington et al. (23)
Adults aged $65+$; representative national survey USA (2002 NHIS) [5837]

Adults; randomized national sample, USA [1035]

Women taking part in SWAN study, USA; community-based sample [3307]

Adults aged $18+$; representative national sample, USA (Medical Expenditure panel survey) [16038]

Adults (African American and Latino); local randomized sample, USA [287]

Adults; representative national survey, USA (2002 NHIS) [31044]

Adults; representative national survey, USA (2002 NHIS) [30278]

Women aged 30-65; community-based samples, USA (ENDOW study) [833]

Use CAM in
past year
(excluding
prayer)

prayer)

Use alternative therapy in previous year

Visit CAM

therapist in 1996

Use CAM to past 12 months

Ever use prayer for health treat sickness in

Ethnicity (Hispanic and Asian $>$ White and Black), gender (female), age ( $>80$ less likely than 65-69), education (high school+), number of health conditions, region (Midwest, West)

Education (higher), health status (poorer), health status (urinary tract problems, chronic pain, back problems, anxiety)

Ethnicity (White $>$ African American > Hispanic/Chinese/

Japanese), age (younger), language (English only $>$ bilingual/ non-English only), income (higher), employed, education (college + ), physical activity (higher), not smoking, healthrelated quality of life (worse), depression (less)

Age (older, $30+$ ), gender (female), education (higher), race (White $>$ Hispanic/African American), region (Midwest and West $>$ South), physical health (poorer)

Financial strain (greater), health status (poorer)

Age (older), gender (female), race (non-Hispanic Black > White; Hispanic $>$ White), income (lower), region (South and Midwest $>$ Northeast), self-rated health (poor), Chronic health conditions (more), use CAMs (biologically based therapies, mind-body medicine, manipulative methods)

Use acupuncture in past 12 months

Use CAM therapy or practitioner in past 5 years
Race/gender interaction (Asian women $>$ white women), education (college + ), region (Northeast and West $>$ South), self-reported health (worse), smoking status (former $>$ never)

Education (high school+), selfreported symptoms (painful intercourse)
None

Income, age, gender, ethnicity

Marital status, menopausal status, perceived stress

Marital status, mental health

Gender, access to care, availability of information, use of public services, depression

Health insurance, education, use alternative medical systems

Birth place, age, income, employment, marital status, health insurance, alcohol use, BMI

Health insurance, income, ethnicity, age, study site, hysterectomy, reported symptoms (pelvic pain, intestinal problems, abnormal bleeding) 
Table 3. Continued

\begin{tabular}{ll}
\hline Study & $\begin{array}{l}\text { Sample characteristics and } \\
\text { sampling strategy }[n]\end{array}$ \\
\hline Buono et al. (19) & $\begin{array}{l}\text { Adults aged 65+; rando- } \\
\text { mized population-based } \\
\text { sample, Italy [655] }\end{array}$ \\
Egede et al. (29) & $\begin{array}{l}\text { Adults aged 18+; rando- } \\
\text { mized national representa- } \\
\text { tive sample, USA (Medical } \\
\text { expenditure panel survey) } \\
\text { [21571] }\end{array}$
\end{tabular}

Fennell (32)

Garrow et al. (33)

Goldstein et al. (34)

Gollschewski et al. (35) Randomized local sample,

Graham et al. (38)
Women aged 48-67; Australia [886]

Adults; representative national survey, USA (2000 NHIS) [24834]

Adults without diabetes; representative national [28625]

Adults with and without cancer; randomized local survey, USA (California health interview survey) [9187]

Adults; representative national survey, USA (2002 NHIS) [20990] survey, USA (2002 NHIS)

CAM use Significant predictors variable

Use alternative therapies

Use practitionerbased CAM in 1996

Use vitamins or minerals

CAM use

CAM provider use in past 12 months

Use herbal therapies

CAM use (excluding prayer)
Gender (female), depression (higher), No chronic somatic disease, spontaneously report pain or discomfort

Gender (female), Ethnicity (Hispanic and Black < White), education (high school + ), region (Northeast, Midwest, South $<$ West), physical health (poor), insurance status (private insurance $<$ uninsured), employment status (employed $>$ unemployed), conditions (diabetes alone, diabetes + other chronic conditions)

Ethnicity (non-Latino white), gender (female), age (older), income (higher), education (higher), health insurance, smoking (former smoker $>$ non-smoker, current smoker $<$ non-smoker), drinking (current or former $>$ non drinker), exercise (increasing), weight (decreasing), number of serious medical conditions (increasing), number of functional limitations (increasing), self-rated health (good)

Age (35-49>18-34, $65+<18-34)$, gender (female), race (White/Hispanic < Black), education (higher), income (higher), region

(South $<$ Northeast, West $>$ Northeast). employed, co-morbidities $(1+)$, Health status (better than last year), functional limitations

Gender (female), age $(65+<18-35)$, race (Latino/ African American < White), poverty level $(300 \%$ and above $>0-99 \%$ ), education (higher), health status (chronic illness or cancer)

Good general health, age ( $<55$ years), Previous use of hormone therapy, participate in BSE in past 2 years, not current user of hormone therapy

Gender (female), education (higher), income (higher), no insurance, self-perceived health status (poorer), region (west), ethnicity (non-Hispanic whites), visited health professional in last 6 months
Non-significant predictors

None reported

Age, marital status, mental health, income

Marital status

Marital status

Insurance status

Employment, menopausal status, social functioning, mental health, pain, professional breast checks, pap smears

Usual source of medical care 
Table 3. Continued

\begin{tabular}{lllll}
\hline Study & $\begin{array}{l}\text { Sample characteristics and } \\
\text { sampling strategy }[n]\end{array}$ & $\begin{array}{l}\text { CAM use } \\
\text { variable }\end{array}$ & Significant predictors & Non-significant predictors \\
\hline
\end{tabular}

Hanssen et al. (42)

Harrison et al. (44)

Hogan et al. (46)

Honda et al. (47)

Hsiao et al. (48)
Adults; national representative/randomized samples, Norway [1000]

Adults; national representative/randomized samples, Denmark [18691]

Adults; national representative/randomized samples, Sweden [1001]

Adults; 5\% systematic regional sample, UK [15465]
Ever used practitionerbased CAM

Ever used CAM

Ever used practitionerbased CAM

Taking one or more herbal supplements

Adults aged $65+$; National population-based sample (Canadian Study of Health and Aging), Canada [1081]

Adults aged 25-74; National representative survey, USA (MIDUS Midlife development in the United States survey) [3032]

South Asians; Randomized local survey, USA (California health interview survey) [109]

Japanese Americans; Randomized local survey, USA (California health interview survey) [179]

Other Asians; Randomized local survey, USA

(California health interview survey) [328]

Chinese Americans;

Randomized local survey, USA (California health interview survey) [451]

Non-Hispanic whites; Randomized local survey, USA (California health interview survey) [3660]

Filipino Americans;

Randomized local survey,

USA (California health interview survey) [269]

CAM use

CAM use in past 12 months

CAM use

CAM use

CAM use

CAM use

CAM use
Education (higher), self-reported health (poorer), visits to medical doctor (more)

Education (higher), self-reported health (poorer), visits to medical doctor (more)

Education (higher)

Age (45-64 more than younger or older), gender (female), ethnicity (white), SES (living in private household), physical activity (active), psychiatric morbidity (possible case), on prescribed medication

Region (BC/Prairies/Ontario), residence (community > institution), gender (female)

Gender (female), education (higher), psychiatric disorders (yes)

English proficiency (not proficient in English and do not speak English)

Age $(51+>$ younger $)$

Age (51 $+>$ younger), Health insurance status (uninsured $>$ insured)

Income ( $>\$ 50000)$, English proficiency (not proficient in English and do not speak English at home), length of US residence (10 years + less likely than US born)

Age $(65+<20-35$ years $)$, Education (higher), health status (chronic illness)

Gender (male), education (college graduate + ), health status (chronic illness, self-rated health very good/excellent), English proficiency (speak English well and English at home)
None reported

None reported

None reported

Self-rated general health, smoking status

Age, family history of neurodegenerative disorder, education, cognitive status

Age, ethnicity, marital status, health insurance coverage, physical disorders

Age, gender, education, income, health status, length of US residence, health insurance status

Gender, education, income, health status, english proficiency, length of US residence, health insurance status

Gender, education, income, health status, english proficiency, length of US residence

Age, gender, education, health status, health insurance status

Gender, income, health status, english proficiency, length of US residence, health insurance status

Age, income, length of US residence, health insurance status 
Table 3. Continued

\begin{tabular}{|c|c|c|c|c|}
\hline Study & $\begin{array}{l}\text { Sample characteristics and } \\
\text { sampling strategy }[n]\end{array}$ & $\begin{array}{l}\text { CAM use } \\
\text { variable }\end{array}$ & Significant predictors & Non-significant predictors \\
\hline
\end{tabular}

Hsiao et al. (49)

Hull et al. (50)

Keith et al. (52)

MacLennan et al. (60)

Adults aged 15+; representative noninstitutionalised population-based survey, Australia (South Australian health omnibus survey 1993) [3004]

Mantyranta et al. (62) Women aged 15-74; randomized representative survey, Finland [1100]

Men aged 15-74; randomized representative survey, Finland [1034]

Matthews et al. (64)
Women; Community sample, USA [829]
Use of Latino specific CAM (curandero)

Use of Asianspecific CAM

(acupuncturist, TCM, green tea, soy products)

Use of American Indian specific

CAM (native

American healers or healing rituals)

Use of African American specific CAM (others pray for your health, garlic)

Use of White specific CAM (massage therapist, osteopath)

Use of faithbased healing

CAM-provider use in past year

Use alternative medicines in past year

Use alternative drugs

Use alternative drugs

Total number of CAM modalities used
Health status (cancer), English proficiency (speak English well)

Age (36-64 > younger), health status (cancer), English proficiency (not proficient in English)

Education (increasing), health status (cancer)

Age ( $>65$ less likely), gender (female), health status (cancer, other chronic illness), length of US residence (US born $>0-9$ years residence)

Gender (female), income (higher), health status (cancer, other chronic illness)

Age $(18-44>75+)$, self-reported health (poorer)

Ethnicity (African American and Hispanic $<$ White), gender (female), marital status (unmarried), region (West), education (higher), self-reported health status (poorer)

Age (15-54 years $>$ older), gender (female), education (postsecondary), work status (employed), drink alcohol at risk level, BMI (overweight/obese $<$ normal), exercise in past 2 weeks (yes)

Education ( $>12$ years), smoking status (non-smoker), Reporting psychosomatic symptoms, physician visits

Education ( $>12$ years), residence (urban $>$ rural), smoking status (non-smoker), exercise weekly ( $3 \mathrm{~h}$ or more), reporting psychosomatic symptoms, physician visits

Sexual orientation (lesbian), health worry (no), perceived discrimination in healthcare settings (yes)
Age, gender, education, income, self-rated health, length of US residence, health insurance status

Gender, education, income, self-rated health, length of US residence, health insurance status

Age, gender, income, selfrated health, health insurance status

Education, income, self-rated health, health insurance status

Age, education, self-rated health, English proficiency, length of US residence, health insurance status

Ethnicity, education, marital status, gender (female), income $(<\$ 50000)$, unemployed

Poverty status

Country of birth, marital status (never married), SES (high/very high), household income $(\$ 20000+)$, history of hypertension

Residence (rural/urban), exercise, self-reported health status, existence of long-standing illness

Self-reported health status, existence of long-standing illness

Age, education, ethnicity, income, Insurance status, chronic illness 
Table 3. Continued

\begin{tabular}{llll}
\hline Study & $\begin{array}{l}\text { Sample characteristics and } \\
\text { sampling strategy }[n]\end{array}$ & $\begin{array}{l}\text { CAM use } \\
\text { variable }\end{array}$ & Significant predictors \\
\hline McCaffrey et al. (65) & $\begin{array}{l}\text { Adults aged 18+; nation- } \\
\text { ally representative survey, } \\
\text { USA (Eisenberg et al. } \\
\text { dataset 30) [2055] }\end{array}$ & $\begin{array}{l}\text { Use of prayer for } \\
\text { health }\end{array}$ & $\begin{array}{l}\text { Gender (female), age (34+ } \\
\text { years }>18-33) \text {, education (high } \\
\text { school +), religion (Christian non- } \\
\text { Roman Catholic), medical condi- } \\
\text { tions (depression, headaches, back } \\
\text { and/or neck pain, gastrointestinal } \\
\text { problems, allergies) }\end{array}$
\end{tabular}

McFarland et al. (66)

Adults; Medical expenditure panel survey, USA [16400]

Adults; Canadian national population health survey, Canada [70884]
Adults aged 55+; Convenience sample, Canada [128]

McMahan et al. (69)

Messerer et al. (70)

Muhajarine et al. (73)

Najm et al. (74) National representative survey USA (Midlife development in the United States survey) [335]

Women; Nationally representative randomized survey, Sweden [5826]

Men; nationally representative randomized survey, Sweden [5596]

Adults aged 20+; Randomized local sample, Canada [818]

Non-Hispanic White adults; Convenience sample, USA [176]
Adults aged 65-74; (compared with
Practitionerbased CAM use

Practitionerbased CAM use

Number of supplements used

Age (20-64 years $>$ older or younger), gender (female), ethnicity (white), education (high school + ), region (West), seen Age (20-64 years $>$ older or younger), gender (female), ethnicity (white), education (high school+), region (West), Selfreported health (excellent $<$ poorgood), problems with instrumental activities of daily living (yes), problems with activities of daily living (no), seen conventional physician in last year

BMI (lower) and positive attitudes towards supplements

CAM use in past 12 months

Gender (female), education (higher), income (higher), spirituality importance (higher), present health status (worse)

Use natural remedies

Use natural remedies

Use of alternative practitioner and physician in past 12 months use of physician in past 12 months)

CAM use in past year

Age (16-44 years $<45-54$ years), physical exercise (heavier), selfreported health status (excellent $<$ good)

Age (65-84 > 45-54 years), physical exercise (heavier), self-reported health status (excellent $<$ good)

Gender (male), chronic back pain, migraine headaches, Psychological distress (higher) conventional physician in last year

Non-significant predictors

None reported

Self-reported health, problems with instrumental activities of daily living, problems with activities of daily living

None reported

Age, self-rated health, number of medications, weight change, dietician's rating of nutritional risk, BMI, money spent on groceries

Not reported

Education, marital status, place of residence, smoking status, BMI

Education, marital status, place of residence, smoking status, BMI

Age, number of chronic conditions, number of disabilities
Age, gender, years in US, born in US, education, perceived health, number of physicians visited 
Table 3. Continued

\begin{tabular}{|c|c|c|c|c|}
\hline Study & $\begin{array}{l}\text { Sample characteristics and } \\
\text { sampling strategy }[n]\end{array}$ & $\begin{array}{l}\text { CAM use } \\
\text { variable }\end{array}$ & Significant predictors & Non-significant predictors \\
\hline & $\begin{array}{l}\text { Hispanic adults; } \\
\text { Convenience sample, USA } \\
{[167]}\end{array}$ & $\begin{array}{l}\text { CAM use in past } \\
\text { year }\end{array}$ & $\begin{array}{l}\text { Years in US }(<10) \text {, number of } \\
\text { physicians visited (higher), } \\
\text { Insurance (private insurance and } \\
\text { no insurance }>\text { managed care or } \\
\text { medicare) }\end{array}$ & $\begin{array}{l}\text { Age, gender, education, } \\
\text { born in US, perceived } \\
\text { health }\end{array}$ \\
\hline & $\begin{array}{l}\text { Asian adults; Convenience } \\
\text { sample, USA [182] }\end{array}$ & $\begin{array}{l}\text { CAM use in past } \\
\text { year }\end{array}$ & $\begin{array}{l}\text { Gender (female), number of phy- } \\
\text { sicians visited (fewer), Insurance } \\
\text { status (Medicare more likely, no } \\
\text { insurance less likely) }\end{array}$ & $\begin{array}{l}\text { Age, years in US, educa- } \\
\text { tion, perceived health }\end{array}$ \\
\hline Ness et al. (75) & $\begin{array}{l}\text { Adults (aged } 52+\text { ); } \\
\text { Randomized subsample } \\
\text { from the nationally repre- } \\
\text { sentative Health and } \\
\text { retirement study, USA } \\
\text { [1099] }\end{array}$ & CAM use & $\begin{array}{l}\text { Gender (female), ethnicity } \\
\text { (Hispanic }<\text { Caucasian), Income } \\
\text { ( } \$ 60000+>\text { less than } \$ 17000) \text {, } \\
\text { No current smoking, limitations } \\
\text { to activities of daily living } \\
\text { (1 limitation }>\text { none) }\end{array}$ & $\begin{array}{l}\text { Age, education, no of } \\
\text { chronic conditions, insur- } \\
\text { ance, hospitalized in past } 2 \\
\text { years, visits to doctor in } \\
\text { past } 2 \text { years, current alco- } \\
\text { hol consumption, limita- } \\
\text { tions in instrumental } \\
\text { activities of daily living }\end{array}$ \\
\hline
\end{tabular}

Newton et al. (76) Women aged 45-64; Local sample of women taking part in a trial, USA [886]

$\mathrm{Ng}$ et al. (77)

Nielsen et al. (79)

Nilsson et al. (80)

Women aged 25-74;

Randomized regional population-based sample of adults, Sweden [2974]

Adults aged 65+; Local comprehensive survey of older adults of Chinese ethnicity, Singapore (subsample of Singapore Chinese longitudinal aging cohort study) [2010]

Men; representative randomized national sample, Denmark (Danish health and morbidity survey 2000) [6963]

Women; representative randomized national sample, Denmark (Danish health and morbidity survey 2000) [7312]

Alternative therapy use

Use natural medicines in past 14 days

Use natural medicines in past 14 days

CAM use
Hot flashes, HRT use (current $<$ never), trouble sleeping, exercise level (higher)

Social support (increasing), arthritis, cancer, disabled in instrumental activities of daily living, current smoker, regular Tai qi, Use sleeping pills, less frequent doctor visits (in those with chronic disease)
Age (increasing, but less in $80+$ years), presence of chronic disease

Age (increasing, but less in $80+$ years), presence of chronic disease, self-perceived general health (less than good),
Menopausal status, education, night sweats

Age, education, marital status, living arrangements, gender, payment for healthcare, chronic disease, hypertension, diabetes, heart disease, stroke, other illness, number of concurrent chronic diseases (higher), using hypnotics, disabled in activities of daily living, regular exerciser, current alcohol use, frequency of doctor visits (in those with no chronic disease), number of prescribed medications, life satisfaction (higher), customarily see same doctor, poor compliance with medicines

Self-perceived general health, education, conventional medicine use

Education, conventional medicine use

Education (secondary or university +), Age (55-64 years), selfperceived health status (poor)
Medical history 
Table 3. Continued

\begin{tabular}{lllll}
\hline Study & $\begin{array}{l}\text { Sample characteristics and } \\
\text { sampling strategy }[n]\end{array}$ & $\begin{array}{l}\text { CAM use } \\
\text { variable }\end{array}$ & Significant predictors & Non-significant predictors \\
& $\begin{array}{l}\text { Men aged 25-74; } \\
\begin{array}{l}\text { Randomized regional } \\
\text { population-based sample of } \\
\text { adults, Sweden [2820] }\end{array}\end{array}$ & CAM use & $\begin{array}{l}\text { Education (secondary or } \\
\text { university +) }\end{array}$ & $\begin{array}{l}\text { Age, medical history (car- } \\
\text { diovascular disorder or } \\
\text { diabetes), self-perceived } \\
\text { health }\end{array}$
\end{tabular}

O'Connor et al. (82)

Rafferty et al. (87)

Raji et al. (88)

Saper et al. (89)

Shmueli et al. (93)

Shmueli et al. (94)

Sturm (99)
Adults aged $40+$; Local randomized sample, USA [4404]

Adults aged $18+$; Local population-based survey, USA (Behavioral risk factor surveillance system) [3764]

Adults aged $77+$; Local population-based sample, USA [365]

Adults aged $18+$; nationally representative sample, USA (Eisenberg 1998 dataset $\left.^{30}\right)[2055]$

Adults aged 45-75; representative sample of Israeli Jewish population [4165]

Adults aged 45-75; representative sample of Israeli Jewish population [2505]

Adults; Nationally representative sample, USA (Healthcare for communities) [9154]

Adults aged 45-75; representative sample of Israeli Jewish population [2003]
Use prayer for health

CAM use

urrent use of herbs

Ever use yoga

Any CAM use der in previous year

Use CAM provider in previous year

Any CAM use

Gender (female), age (young and old less likely), education (higher), insurance (private or none), region (West), number of chronic conditions (higher), mental health (worse)
Gender (female), education (some college or more less likely to pray), employment, marital status (married or widowed)

Gender (female), ethnicity (White > Black), education (higher), self-perceived general health status (poorer)

Gender (female)

Age (34-53 years $>54+$ years), gender (female), religious preference (none or other $>$ Christian), education ( $>$ high school), urbanicity (metropolitan), no children under 18 living in household, CAM use other than yoga (any, athy, energy healing, acupuncture), specific health conditions (lung disease)

Survey year (2000), health-related quality of life (poorer), gender (female), age (younger), economic status (good), residence (big city), education (higher), origin (USSR less likely)

Gender (female), education (high school)

Gender (female), age (younger), education (higher), economic status (very good or good), health plan (Meuhdet plan $>$ other three plans), health-related quality of life (worse) relaxation techniques, homeop-
Age, chronic condition

Age, income

Ethnicity, age, place of birth, medical condition (diabetes, coronary artery disease), physician visits in past year

Insurance

Religiosity, age, education, economic status, ethnicity, residential area, marital status, health plan, chronic health problems, healthrelated quality of life

Religiosity, ethnicity, residential area (big city), marital status, chronic health problems

Income, ethnicity 
Table 3. Continued

\begin{tabular}{|c|c|c|c|c|}
\hline Study & $\begin{array}{l}\text { Sample characteristics and } \\
\text { sampling strategy }[n]\end{array}$ & $\begin{array}{l}\text { CAM use } \\
\text { variable }\end{array}$ & Significant predictors & Non-significant predictors \\
\hline Unutzer et al. (104) & $\begin{array}{l}\text { Adults; randomized } \\
\text { national representative } \\
\text { sample, USA [9585] }\end{array}$ & CAM use & $\begin{array}{l}\text { Mental disorder (major depres- } \\
\text { sion, panic disorder more likely, } \\
\text { dysthymia less likely), number of } \\
\text { chronic medical problems (higher), } \\
\text { gender (female), age }(60+ \\
<30-59 \text { years), education } \\
\text { (higher), region (West }>\text { South), } \\
\text { health insurance (private) }\end{array}$ & $\begin{array}{l}\text { Mental disorder (GAD, } \\
\text { mania/psychosis), sub- } \\
\text { stance abuse, race, work } \\
\text { status }\end{array}$ \\
\hline
\end{tabular}

\begin{tabular}{|c|c|c|c|c|}
\hline Upchurch et al. (105) & $\begin{array}{l}\text { Women aged } 18+\text {; repre- } \\
\text { sentative national survey, } \\
\text { USA (1999 NHIS) [17399] }\end{array}$ & CAM use & $\begin{array}{l}\text { Age (older), ethnicity (Black non- } \\
\text { Hispanic, Hispanic and } \\
\text { Asian }<\text { White), Nativity (US } \\
\text { Born), education (higher), income } \\
(>\$ 20000), \text { region (Midwest \& } \\
\text { West }>\text { South; Northeast } \\
<\text { South), self-rated health status } \\
\text { (worse) }\end{array}$ & Insurance status \\
\hline Wolsko et al. (109) & $\begin{array}{l}\text { Adults aged } 18+; \\
\text { randomized national } \\
\text { representative sample, USA } \\
\text { (Eisenberg et al. } 1998 \\
\text { dataset 30) [2055] } \\
\end{array}$ & $\begin{array}{l}\text { Use of a CAM } \\
\text { provider among } \\
\text { people who used } \\
\text { a given CAM } \\
\text { therapy }\end{array}$ & $\begin{array}{l}\text { Visits to conventional practi- } \\
\text { tioners (more), gender (female), } \\
\text { use of CAM for diabetes, use } \\
\text { CAM for cancer, use CAM for } \\
\text { back or neck problems }\end{array}$ & $\begin{array}{l}\text { Age, race, region, educa- } \\
\text { tion, income, presence of } \\
\text { psychiatric disorder }\end{array}$ \\
\hline
\end{tabular}

Note. Due to space limitations we have in most cases presented one analysis per article. Where multiple analyses are present in the original studies the analysis pertaining to overall CAM use in the whole sample has been selected. Where multiple analyses pertain to CAM use in different subsamples of participants, all analyses are presented.

that relevant studies were overlooked as search terms for specific CAM modalities, such as homeopathy or acupuncture, were not used.

A number of specific recommendations for future work stem from our review of both the quality of the studies and their results. The overwhelming dominance of US-based research was disappointing - more large-scale surveys of CAM use and its predictors need to be conducted in other countries. The quality of studies was mixed, and in the future this could be improved by: employing prospective designs (particularly in relation to health status and CAM use); using consistent boundaries across studies when categorizing participants' ages; detailed reporting of sampling strategies and response rates; using measures of CAM use (and demographic factors and health status) that have been pilot-tested and shown to be reliable and valid. Overall such a large number of diverse studies have now been carried out in this area that future reviews would benefit from taking a more circumscribed approach and focusing on specific issues, such as predictors of the use of specific CAM modalities or the association between CAM use and specific individual demographic or health factors.

\section{Acknowledgements}

Dr F.L.B. was supported by an ESRC-CASE Studentship in collaboration with Boots plc. Dr G.T.L. post is funded by a grant from the Maurice Laing Foundation.

\section{References}

1. Thomas KJ, Nicholl JP, Coleman P. Use and expenditure on complementary medicine in England: a population based survey. Complement Ther Med 2001;9:2-11.

2. Chang HY, Wallis M, Tiralongo E. Use of complementary and alternative medicine among people living with diabetes: literature review. $J$ Adv Nurs 2007;58:307-19.

3. Slader CA, Reddel HK, Jenkins CR, Armour CL, BosnicAnticevich SZ. Complementary and alternative medicine use in asthma: Who is using what? Respirology 2006;11:373-87.

4. Wootton JC, Sparber A. Surveys of complementary and alternative medicine: part I. General trends and demographic groups. J Altern Complement Med 2001;7:195-208.

5. Adams J, Sibbritt D, Easthope G, Young AF. The profile of women who consult alternative health practitioners in Australia. Med $J$ Aust 2003;179:297-300.

6. Arcury TA, Suerken CK, Grzywacz JG, Bell RA, Lang W, Quandt SA. Complementary and alternative medicine use among older adults: ethnic variation. Ethn Dis 2006;16:723-31.

7. Arcury TA, Preisser JS, Gesler WM, Sherman JE. Complementary and alternative medicine use among rural residents in western North Carolina. Complement Health Pract Rev 2004;9:93-102.

8. Astin JA. Why patients use alternative medicine. Results of a national study. JAMA 1998;279:1548-53.

9. Ayranci U, Son N, Son O. Prevalence of nonvitamin, nonmineral supplement usage among students in a Turkish university. $B M C$ Public Health 2005;5:47.

10. Bair YA, Gold EB, Greendale GA, Sternfeld B, Adler SR, Azari R, et al. Ethnic differences in use of complementary and alternative medicine at midlife: longitudinal results from SWAN participants. Am J Public Health 2002;92:1832-40.

11. Barnes PM, Powell-Griner E, McFann K, Nahin RL. Complementary and alternative medicine use among adults: United States, 2002. Advance Data From Vital and Health Statistics Hyattsville, Maryland: National Center for Health Statistics, 2004; No. 343. 
12. Bausell RB, Lee W-L, Berman BM. Demographic and healthrelated correlates of visits to complementary and alternative medical providers. Med Care 2001;39:190-6.

13. Bazargan M, Norris K, Bazargan-Hejazi S, Akhanjee L, Calderon JL, Safvati SD, et al. Alternative healthcare use in the under-served population. Ethn Dis 2005;15:531-9.

14. Bell RA, Suerkin C, Quandt SA, Grzywacz JG, Lang W, Arcury TA. Prayer for health among U.S. adults: the 2002 national health interview survey. Complement Health Pract Rev 2005; 10:175-88.

15. Bell RA, Suerkin CK, Grzywacz JG, Lang W, Quandt SA, Arcury TA. Complementary and alternative medicine use among adults with diabetes in the United States. Altern Ther Health Med 2006; 12:16-22.

16. Bell RA, Suerken CK, Grzywacz JG, Lang W, Quandt SA, Arcury TA. CAM use among older adults age 65 or older with hypertension in the United States: general use and disease treatment. J Altern Complement Med 2006;12:903-9.

17. Bernstein JH, Shuval JT. Nonconventional medicine in Israel: consultation patterns of the Israeli population and attitudes of primary care physicians. Soc Sci Med 1997;44:1341-8.

18. Brownie S, Rolfe M. Health characteristics of older Australian dietary supplement users compared to non-supplement users. Asia Pac J Clin Nutr 2004;13:365-71.

19. Buono MD, Urciuoli O, Marietta P, Padoani W, Leo DD. Alternative medicine in a sample of 655 community-dwelling elderly. J Psychosom Res 2001;50:147-54.

20. Burg MA, Hatch RL, Neims AH. Lifetime use of alternative therapy: a study of Florida residents. South Med J 1998;91:1126-31.

21. Burke A, Upchurch DM, Dye C, Chyu L. Acupuncture use in the United States: findings from the National Health Interview Survey. J Altern Complement Med 2006;12:639-48.

22. Cappuccio FP, Duneclift SM, Atkinson RW, Cook DG. Use of alternative medicines in a multi-ethnic population. Ethn Dis 2001; 11:11-8.

23. Cherrington A, Lewis CE, McCreath HE, Herman CJ, Richter DL, Byrd T. Association of complementary and alternative medicine use, demographic factors, and perimenopausal symptoms in a multiethnic sample of women - The ENDOW study. Fam Community Health 2003;26:74-83.

24. Conboy L, Patel S, Kaptchuk TJ, Gottlieb B, Eisenberg D, Acevedo-Garcia D. Sociodemographic determinants of the utilization of specific types of complementary and alternative medicine: an analysis based on a nationally representative survey sample. $J$ Alter Complement Med 2005;11:977-94.

25. Dessio W, Wade C, Chao M, Kronenberg F, Cushman LF, Kalmuss D. Religion, spirituality, and healthcare choices of African-American women: results of a national survey. Ethn Dis 2004;14:189-97.

26. Druss BG, Rohrbaugh R, Korsten T, Hoff R, Rosenheck RA. Use of alternative medicine in major depression. Psychiatr Serv 1998:49:1397.

27. Druss BG, Rosenheck RA. Association between use of unconventional therapies and conventional medical services. JAMA 1999;282:651-6

28. Druss BG, Rosenheck RA. Use of practitioner-based complementary therapies by persons reporting mental conditions. Arch Gen Psychiatry 2000;57:708-14.

29. Egede LE, Ye X, Zheng D, Silverstein MD. The prevalence and pattern of complementary and alternative medicine use in individuals with diabetes. Diabetes Care 2002;25:324-9.

30. Eisenberg DM, Davis RB, Ettner SL, Appel S, Wilkey S, Rompay $\mathbf{M}$, et al. Trends in alternative medicine use in the United States, 1990-1997. Results of a followup national survey. JAMA 1998;280:1569-75.

31. Factor-Litvak P, Cushman LF, Kronenberg F, Wade C, Kalmuss D. Use of complementary and alternative medicine among women in New York City: A pilot study. $J$ Altern Complement Med 2001;7:659-66.

32. Fennell D. Determinants of supplement usage. Prev Med 2004;39:932-9.

33. Garrow D, Egede LE. National patterns and correlates of complementary and alternative medicine use in adults with diabetes. $J$ Altern Complement Med 2006;12:895-902.
34. Goldstein MS, Brown ER, Ballard-Barbash R, Morgenstern H, Bastani R, Lee J, et al. The use of complementary and alternative medicine among California adults with and without cancer. Evid Based Complement Alternat Med 2005;2:557-65.

35. Gollschewski S, Anderson D, Skerman H, Lyons-Wall P. Associations between the use of complementary and alternative medications and demographic, health and lifestyle factors in mid-life Australian women. Climacteric 2005;8:271-8.

36. Gordon NP, Lin TY. Use of complementary and alternative medicine by the adult membership of a large northern California health maintenance organization, 1999. J Ambul Care Manage 2004;27:12-24.

37. Gozum S, Unsal A. Use of herbal therapies by older, communitydwelling women. $J$ Adv Nurs 2004:46:171-8.

38. Graham RE, Ahn AC, Davis RB, O'Connor BB, Eisenberg DM, Phillips RS. Use of complementary and alternative medical therapies among racial and ethnic minority adults: results from the 2002 national health interview survey. J Natl Med Assoc 2005;97:535-45.

39. Gray CM, Tan AWH, Pronk NP, O'Connor PJ. Complementary and alternative medicine use among health plan members. A crosssectional survey. Eff Clin Pract 2002;5:17-22.

40. Grzywacz JG, Lang W, Suerkin C, Quandt SA, Bell RA, Arcury TA. Age, race, and ethnicity in the use of complementary and alternative medicine for health self-management. $J$ Aging Health 2005; 17:547-72.

41. Grzywacz JG, Suerkin CK, Quandt SA, Bell RA, Lang W, Arcury TA. Older adults' use of complementary and alternative medicine for mental health: findings from the 2002 National health interview survey. J Altern Complement Med 2006;12:467-73.

42. Hanssen B, Grimsgaard S, Launsø L, Fønnebø V, Falkenberg T, Rasmussen NKR. Use of complementary and alternative medicine in the scandinavian countries. Scand $J$ Prim Health Care 2005;23:57-62.

43. Harris PF, Remington PL, Trentham-Dietz A, Allen CI, Newcomb PA. Prevalence and treatment of menopausal symptoms among breast cancer survivors. $J$ Pain Symptom Manage 2002;23:501-9.

44. Harrison RA, Holt D, Pattison DJ, Elton PJ. Who and how many people are taking herbal supplements? A survey of 21,923 adults. Int J Vitam Nutr Res 2004;74:183-6.

45. Hendershot GE. Mobility limitations and complementary and alternative medicine: are people with disabilities more likely to pray? Am J Public Health 2003;93:1079-80.

46. Hogan DB, Maxwell CJ, Ebly EM. Use of complementary and alternative medicines by older individuals: results from the Canadian study of health and aging. Geriatrics today. $J$ Can Geriatr Soc 2003;6:21-5.

47. Honda K, Jacobson JS. Use of complementary and alternative medicine among United States adults: the influences of personality, coping strategies, and social support. Prev Med 2005;40:46-53.

48. Hsiao A-F, Wong MD, Goldstein MS, Becerra LS, Cheng EM, Wenger NS. Complementary and alternative medicine use among Asian-American subgroups: prevalence, predictors, and lack of relationship to acculturation and access to conventional health care. J Altern Complement Med 2007:12:1003-10.

49. Hsiao A-F, Wong MD, Goldstein MS, Yu HJ, Andersen RM, Brown ER, et al. Variation in complementary and alternative medicine (CAM) use across racial/ethnic groups and the development of ethnic-specific measures of CAM use. J Altern Complement Med 2006;12:281-90.

50. Hull SK, Daaleman TP, Thaker S, Pathman DE. A prevalence study of faith-based healing in the rural southeastern United States. South Med $J$ 2006;99:644-53.

51. Jorm AF, Rodger B, Christensen H. Use of medications to enhance memory in a large community sample of 60-64 year olds. Int Psychogeriatr 2004;16:209-17.

52. Keith VM, Kronenfeld JJ, Rivers PA, Liang S. Assessing the effects of race and ethnicity on use of complementary and alternative therapies in the USA. Ethn Health 2005;10:19-32.

53. Kennedy J. Herb and supplement use in the US adult population. Clin Ther 2005;27:1847-58.

54. Kong SC, Hurlstone DP, Pocock CY, Walkington LA, Farquharson NR, Bramble MG, et al. The incidence of 
self-prescribed oral complementary and alternative medicine use by patients with gastrointestinal diseases. $J$ Clin Gastroenterol 2005;39:138-41.

55. Kronenberg F, Cushman LF, Wade CM, Kalmuss D, Chao MT. Race/ethnicity and women's use of complementary, and alternative medicine in the United States: results of a national survey. $\mathrm{Am} \mathrm{J}$ Public Health 2006;96:1236-42.

56. Lafferty WE, Tyree PT, Bellas AS, Watts CA, Lind BK, Sherman KJ, et al. Insurance coverage and subsequent utilization of complementary and alternative medicine providers. Am J Manag Care 2006;12:397-404.

57. Lim MK, Sadarangani P, Chan HL, Heng JY. Complementary and alternative medicine use in multiracial Singapore. Complement Ther Med 2005;13:16-24.

58. Mackenzie ER, Taylor L, Bloom BS, Hufford DJ, Johnson PC. Ethnic minority use of complementary and alternative medicine (CAM): A national probability survey of CAM utilizers. Altern Ther Health Med 2003;9:50-6.

59. MacLennan AH, Myers SP, Taylor AW. The continuing use of complementary and alternative medicine in South Australia: costs and beliefs in 2004. Med J Aust 2006;184:27-31.

60. MacLennan AH, Wilson DH, Taylor AW. Prevalence and cost of alternative medicine in Australia. Lancet 1996;347:569-73.

61. MacLennan AH, Wilson DH, Taylor AW. The escalating cost and prevalence of alternative medicine. Prev Med 2002;35:166-73.

62. Mantyranta T, Hemminki E, Koskela K. Use of alternative drugs in Finland. Pharmacoepidemiol Drug Saf 1999;8:23-9.

63. Martin KJ, Jordan TR, Vassar AD, White DB. Herbal and nonherbal alternative medicine use in northwest Ohio. Ann Pharmacother 2002;36:1862-9.

64. Matthews AK, Hughes TL, Osterman GP, Kodl MM. Complementary medicine practices in a community-based sample of lesbian and heterosexual women. Health Care Women Int 2005;26:430-47.

65. McCaffrey AM, Eisenberg DM, Legedza ATR, Davis RB, Phillips RS. Prayer for health concerns - Results of a national survey on prevalence and patterns of use. Arch Intern Med 2004; 164:858-62.

66. McFarland B, Bigelow D, Zani B, Newsom J, Kaplan M. Complementary and alternative medicine use in Canada and the United States. Am J Public Health 2002;92:1616-8.

67. McGregor KJ, Peay ER. The choice of alternative therapy for health care: testing some propositions. Soc Sci Med 1996;43:1317-27.

68. McKenzie J, Keller HH. Who are the users of vitamin-mineral and herbal preparations among community-living older adults? Can $J$ Aging 2007;22:167-75.

69. McMahan S, Lutz R. Alternative therapy use among the young-old (Ages 65 to 74): an evaluation of the MIDUS database. J ApplGerontol 2007;23:91-103.

70. Messerer M, Johansson SE, Wolk A. Sociodemographic and health behaviour factors among dietary supplement and natural remedy users. Eur J Clin Nutr 2001;55:1104-10.

71. Mikhail N, Wali S, Ziment I. Use of alternative medicine among Hispanics. J Altern Complement Med 2004;10:851-9.

72. Mishra SI, Hess J, Luce PH. Predictors of indigenous healer use among Samoans. Altern Ther Health Med 2003;9:64-9.

73. Muhajarine N, Neudorf C, Martin K. Concurrent consultations with physicians and providers of alternative care: results from a population-based study. Can J Public Health 2002;91:449-53.

74. Najm W, Reinsch S, Hoehler F, Tobis J. Use of complementary and alternative medicine among the ethnic elderly. Altern Ther Health Med 2003;9:50-7.

75. Ness J, Cirillo DJ, Weir DR, Nisly NL, Wallace RB. Use of complementary medicine in older Americans: results from the health and retirement study. Gerontologist 2005;45:516-24.

76. Newton KM, Buist DSM, Keenan NL, Anderson LA, LaCroix AZ. Use of alternative therapies for menopause symptoms: results of a population-based survey. Obstet Gynecol 2002;100:18-25.

77. Ng TP, Tan CH, Kua EH. The use of Chinese herbal medicines and their correlates in Chinese older adults: the Singapore Chinese longitudinal aging study. Age Ageing 2004;33:135-42.

78. Ni HY, Simile C, Hardy AM. Utilization of complementary and alternative medicine by United States adults - results from the 1999 National health interview survey. Med Care 2002;40:353-8.
79. Nielsen MW, Hansen EH, Rasmussen NK. Use of natural medicines in the Danish population: a national cross-sectional survey. Ann Pharmacother 2005;39:1534-8.

80. Nilsson M, Trehn G, Asplund K. Use of complementary and alternative medicine remedies in Sweden. A population-based longitudinal study within the northern Sweden MONICA Project. J Intern Med 2001;250:225-33.

81. Norheim AJ, Fonnebo V. A survey of acupuncture patients: results from a questionnaire among a random sample in the general population in Norway. Complement Ther Med 2000;8:187-92.

82. O'Connor PJ, Pronk NP, Tan A, Whitebird RR. Characteristics of adults who use prayer as an alternative therapy. Am J Health Promot 2005;19:369-75.

83. Oldendick R, Coker AL, Wieland D, Raymond JI, Probst JC, Schell BJ, et al. Population-based survey of complementary and alternative medicine usage, patient satisfaction, and physician involvement. South Med J 2000;93:375-81.

84. Owens JE, Taylor AG, Degood D. Complementary and alternative medicine and psychologic factors: toward an individual differences model of complementary and alternative medicine use and outcomes. J Altern Complement Med 1999;5:529-41.

85. Paramore LC. Use of alternative therapies: estimates from the 1994 Robert Wood Johnson foundation national access to care survey. J Pain Symptom Manage 1997;13:83-9.

86. Quandt SA, Chen H, Grzywacz JG, Bell RA, Lang W, Arcury TA. Use of complementary and alternative medicine by persons with arthritis: results of the national health interview study. Arthritis Care Res 2005;53:748-55.

87. Rafferty AP, McGee HB, Miller CE, Reyes M. Prevalence of complementary and alternative medicine use: state-specific estimates from the 2001 behavioral risk factor surveillance system. Am J Public Health 2002;92:1598-600.

88. Raji MA, Kuo Y-F, Snih SA, Sharaf BM, Loera JA. Ethnic differences in herb and vitamin/mineral use in the elderly. Ann Pharmacother 2005;39:1019-23.

89. Saper RB, Eisenberg DM, Davis RB, Culpepper L, Phillips RS. Prevalence and patterns of adult yoga use in the United States: Results of a national survey. Altern Ther Health Med 2004;10:44-9.

90. Saydah SH, Eberhardt MS. Use of complementary and alternative medicine among adults with chronic diseases: United States 2002. J Altern Complement Med 2006;12:805-12.

91. Schaffer DM, Gordon NP, Jensen CD, Avins AL. Nonvitamin, nonmineral supplement use over a 12-month period by adult members of a large health maintenance organization. $J$ Am Diet Assoc 2003;103:1500-5.

92. Shankar PR, Kumar P, Theodore AM, Partha P, Shenoy N. A survey of drug use patterns in western Nepal. Singapore Med $J$ 2007;44:352-6.

93. Shmueli A, Shuval J. Complementary and alternative medicine: beyond users and nonusers. Complement Ther Med 2006;14:261-7.

94. Shmueli A, Shuval J. Use of complementary and alternative medicine in Israel: 2000 vs. 1993. Isr Med Assoc J 2004;6:3-8.

95. Sibbritt D, Adams J, Easthope G, Young A. Complementary and alternative medicine (CAM) use among elderly Australian women who have cancer. Support Care Cancer 2003;11:548-50.

96. Sibbritt DW, Adams J, Young AF. A longitudinal analysis of mid-age women's use of Complementary and Alternative Medicine (CAM) in Australia, 1996-1998. Women Health 2004:40:41-56.

97. Singh V, Raidoo DM, Harries CS. The prevalence, patterns of usage and people's attitude towards complementary and alternative medicine (CAM) among the Indian community in Chatsworth, South Africa. BMC Complement Altern Med 2004;4:3 doi:10.1186/ 1472-6882-4-3.

98. Steyer TE, King DE, Mainous AG, Gilbert G. Use of nutritional supplements for the prevention and treatment of hypercholesterolemia. Nutrition 2003;19:415-8.

99. Sturm R. Patient risk-taking attitude and the use of complementary and alternative medical services. J Altern Complement Med 2000;6:445-8.

100. Thomas KJ, Coleman P. Use of complementary or alternative medicine in a general population in Great Britain. Results from the national omnibus survey. $J$ Public Health 2004;26:152-7. 
101. Tindle HA, Davis RB, Phillips RS, Eisenberg DM. Trends in use of complementary and alternative medicine by US adults: 1997-2002. Altern Ther Health Med 2005;11:42-9.

102. Tindle HA, Wolsko P, Davis RB, Eisenberg DM, Phillips RS, McCarthy EP. Factors associated with the use of mind body therapies among United States adults with musculoskeletal pain. Complement Ther Med 2005;13:155-64.

103. Tsai PS, Ke TL, Huang CJ, Hsaio FH, Wang MY, Cheng YH. Demographic characteristics and perceived health status of users of folk therapies in Taiwan. J Altern Complement Med 2006;12:549-54.

104. Unutzer J, Klap R, Sturm R, Young AS, Marmon T, Shatkin J, et al. Mental disorders and the use of alternative medicine: Results from a national survey. Am J Psychiatry 2000;157:1851-7.

105. Upchurch DM, Chyu L. Use of complementary and alternative medicine among American women. Women's Health Issues 2005;15:5-13.

106. Vandvik PO, Lydersen S, Farup PG. Prevalence, comorbidity and impact of irritable bowel syndrome in Norway. Scand $J$ Gastroenterol 2006:41:650-6.

107. Verkasalo MA, Raitakari OT, Viikari J, Marniemi J, Savilahti E. Undiagnosed silent coeliac disease: a risk for underachievement? Scand J Gastroenterol 2005;40:1407-12.

108. Wiles J, Rosenberg MW. 'Gentle caring experience'; seeking alternative health care in Canada. Health Place 2001;7:209-24.

109. Wolsko PM, Eisenberg DM, Davis RB, Ettner SL, Phillips RS. Insurance coverage, medical conditions, and visits to alternative medicine providers: Results of a national survey. Arch Intern Med 2002;162:281-7.
110. Wolsko PM, Eisenberg DM, Davis RB, Phillips RS. Use of mindbody medical therapies. Results of a national survey. J Gen Intern Med 2004;19:43-50.

111. Yamashita H, Tsukayama H, Sugushita C. Popularity of complementary and alternative medicine in Japan: a telephone survey. Complement Ther Med 2002;10:84-93.

112. Yeh GY, Eisenberg DM, Davis RB, Phillips RS. Use of complementary and alternative medicine among persons with diabetes mellitus: results of a national survey. Am $J$ Public Health 2002;92:1648-52.

113. Yoon SL. Racial/ethnic differences in self-reported health problems and herbal use among older women. J Natl Med Assoc 2006;98:918-25

114. Green CA, Pope CR. Gender, psychosocial factors and the use of medical services: a longitudinal analysis. Soc Sci Med 1999;48:1363-72.

115. Department of Health. General Household Survey 1998. London: HMSO, 1998.

116. Andersen R, Newman JF. Societal and individual determinants of medical care utilization in the United States. Milbank Mem Fund $Q$ 1973;51:95-124.

117. de Boer AGEM, Wijker W, de Haes HCJM. Predictors of health care utilization in the chronically ill: a review of the literature. Health Policy 1997;42:101-15.

118. Tessler R, Mechanic D, Dimond M. The effect of psychological distress on physician utilization: a prospective study. $J$ Health Soc Behav 1976;17:353-64.

119. Rosenstock IM. Why people use health services. Milbank Mem Fund $Q$ 1966:44:94-124.

Received November 13, 2006; accepted February 25, 2008 


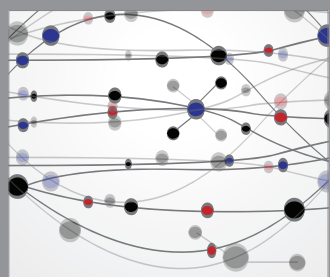

The Scientific World Journal
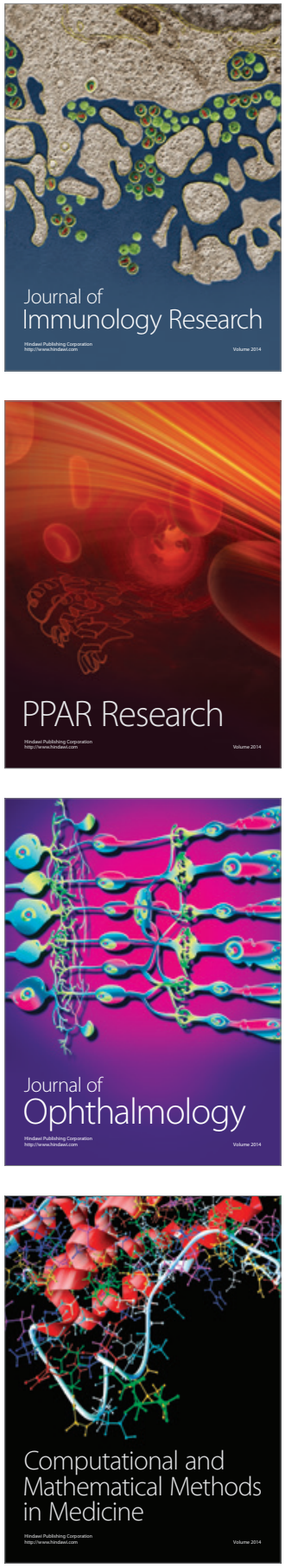

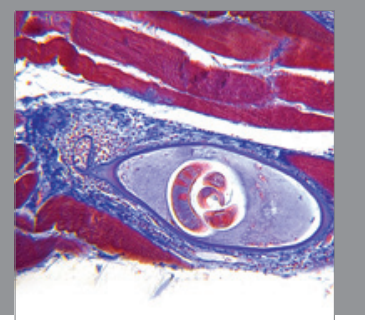

Gastroenterology

Research and Practice
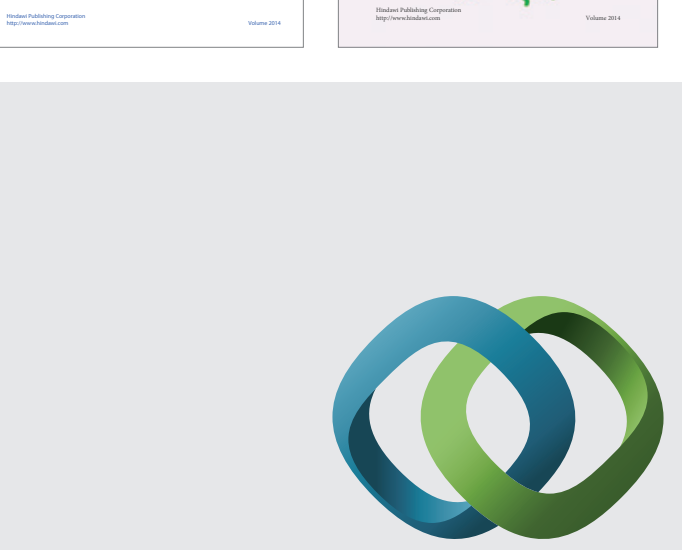

\section{Hindawi}

Submit your manuscripts at

http://www.hindawi.com
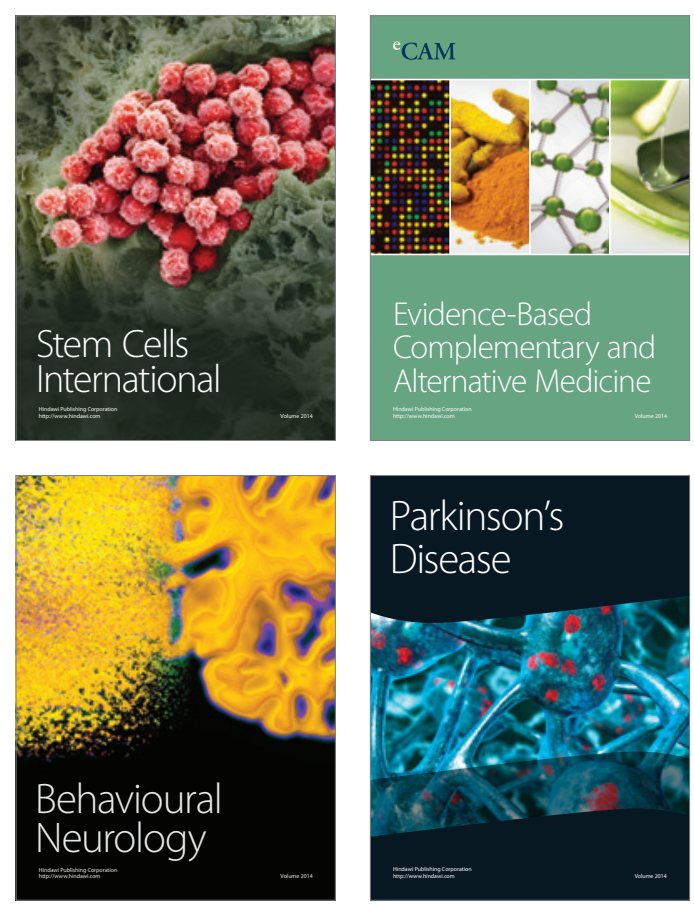

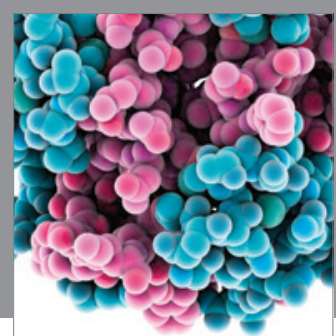

Journal of
Diabetes Research

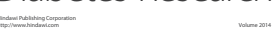

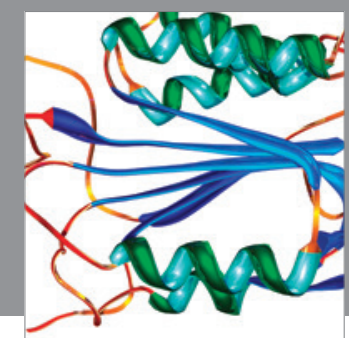

Disease Markers
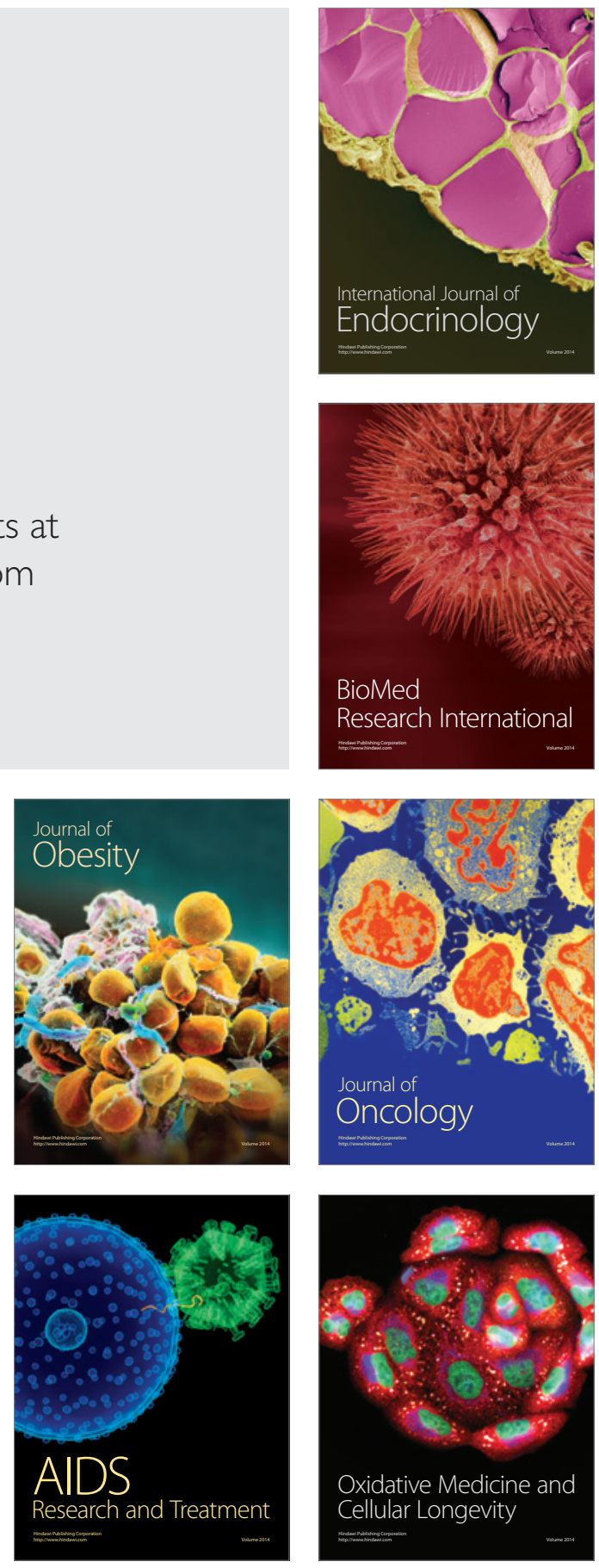